\title{
QUALITY ENGINEERING TRANSFORMATION OVER THE YEARS AND ISSUES - A REVIEW
}

\author{
Pappu Rama Subramaniam \\ Department of Mechanical Engineering \\ LENDI Institute of Engineering and Technology, \\ Vizianagaram, Andhra Pradesh, India
}

\begin{abstract}
Traditional quality management and monitoring has been shown to be unsuccessful. Today, emerging companies are vying for more value to the consumer in order to ensure their maximum success and sustainability. Many businesses want to ensure that their goods and services are of high quality in order to attract customers. The current situation is implementing quality engineering solutions in industries. Quality engineering is the method of evaluating, handling, designing, and maintaining various systems in compliance with high standards. This method ensures that each stage of the product development cycle is subjected to a thorough inspection by quality engineers, reducing possible losses by eliminating defects from the start. Furthermore, highquality maintenance is important and should be made available for a long time after the product has been shipped.
\end{abstract}

Customers' preferences are shifting significantly, necessitating improvements in design and production technology, which is becoming increasingly critical in satisfying individual customers. This necessitates paying particular attention to quality engineering.

The paper starts with a review on quality emphasis over the last 37 years, quality concepts, and quality model evolution followed by i) a contrast of quality management and quality engineering, ii) developments in quality engineering tools and techniques, such as statistical process control (SPC), design of experiment (DoE), Taguchi processes, and quality function (QFD). This paper also looks at quality engineering-related problems. There are brief reviews of recent developments in well-known quality tools, such as statistical process control, quality function deployment, and design of experiment. The aim of this paper is to place quality engineering in context and emphasise its significance, as well as to present some issues at the frontiers of quality engineering.

Keywords - Keywords Quality, Techniques, Statistical process control

\section{INTRODUCTION}

All public, private and services organizations are apprehensive of quality problems. Through the implementation of quality tools and techniques, beyond the conventional approach quality continues to improve. Quality tools, strategies, principles, and methodologies have been improved to meet new demands. A greater emphasis is often laid on the management and conceptual aspects of quality by managers than on the assistive technologies of quality (quality engineering) despite its evaluative and fruitful role in inducing quality. Quality engineering has progressed significantly, as shown by numerous scientific publications. According to general trends in quality engineering research the tools are being improved, assimilated, computerized, and their application bases are being expanded. Contributions in multiple-response optimization, intelligent quality systems, multivariate SPC, realistic and easy-to-follow instructions for putting different tools into practice, with suggestions for further research are among them.

\section{LITERATURE REVIEW ON QUALITY FOCUS}

Various theories on quality were formulated as a result of

i) Changes in organization's business traits,

ii) changes that allow bettering and adapting to its survival with ever-changing demands over time.

Quality pundits have always strived hard to provide up-todate information on the various meanings of the word "quality" and steps in the evolution of quality management. Professionals who have spearheaded quality had different authoritative and incisive perspectives over the last two decades on growing demand for quality management.

Romanian-American engineer and management consultant, Joseph Moses Juran voiced Products and services quality has interested researchers and practitioners for centuries (1995).

An American-born quality expert and the originator's of business quality during the twentieth century Dr. Armand Vallin Feigenbaum has emphasized TQM is the most powerful tool of growth and sustainable business expansion (1999).

Mohamed Zairi a British academic and researcher in the field of total quality management and excellence management 


\section{International Journal of Engineering Applied Sciences and Technology, 2021 \\ Vol. 5, Issue 10, ISSN No. 2455-2143, Pages 247-256 \\ Published Online February 2021 in IJEAST (http://www.ijeast.com)}

came out with "Teachings of the so called quality gurus in the twentieth century made quality management a high-priority area" (2013).

Gilles Barouch and Stéphane Kleinhans of the Department of Operation Management and Information Systems, Kedge Business School, Talence, France argued that QM seems to have gained an equal amount of approvals as disapprovals (2015).

Scholars B Aquilani, C Silvestri, A Ruggieri, and C Gatti minutely accounted relationship between TQM and firm performance (2017). They also concluded that research within this domain is in the beginning.

Professor J.Maiti and his associates P.Kumar and A.Gunasekaran concluded requirement of a more detailed understanding of QM's performance effects by sophisticated research study (2018).

The Scientific debate till continues regarding the importance and capability of quality initiatives and is far from settled.

Quality has had multiple and messy definitions, furthermore, complex and multiple views associated with quality have made research advances difficult. However, according to scholars' Carol A Reeves \& David A Bednar, the solution is not to create a single definition that takes into account all possible variables, instead, the aim should be to create comparable models and concepts that take into account previously overlooked variables (1994).

Alan Brown of School of Management, Edith Cowan University, Joondalup, Australia asserts that the idea of quality has existed and during the 1980s it really became widely publicized and supported. Academics started researching the phenomenon, success stories and quality awards emerged and journals specifically devoted to it were launched (2013).

Professor Dahlgaard-Park, Lund University et al argue that a clearer theoretical foundation of TQM is needed to better understand TQM's current state. (2018).

As per Professor Raine Isaksson and scholar $\mathbf{M}$. Fredriksson similarities and differences between different quality philosophies is necessary in order to conduct scientific as well as university teaching activities (2018).

In a similar mission Dr Everard A. Van Kemenade and Professor Teun W. Hardjono declare that to understand current directions and future needs, a new paradigm is needed to clarify QM's current position (2019).

Is that this solely an issue of academics with no importance to the practical shop-floor and everyday business life? No, Gilles Barouch and Frederic Ponsignon come up saying managers' familiarity is a condition for the success of QM programmes (2016).

According to Aquilani et al,, the scholarly literature emphasizes that managers need to be able to navigate between specified circumstances, industries, countries, dimensions, products, services, etc., to detect their organization's critical success factors (CSFs), situations, goals, strategies, and expected performances - starting from business model and management approach (2017).

Similarly, Kumar et al. find that having a clear understanding of the differences and similarities between QM systems, concepts, methodologies, tools/techniques, and evaluation models among managers and engineers aids the implementation process (2018).

In total, it is apparent that theoretical and practical initiatives concerning quality go hand in hand. A concentrated understanding of research analysis on quality topics over time helps as information to practice and progress.TQM is a ground-breaking approach to management. TQM is not commonly used in some industries, despite the fact that it has been widely accepted.

\section{DEFINITIONS OF QUALITY AND CUSTOMER FOCUS BY SOME PROMINENT QUALITY GURUS}

The bottom line of some definitions of Quality by various quality gurus is compiled in Table I below:

\begin{tabular}{|l|l|}
\hline Quality Guru & Definition \\
\hline Dr. Walter A. Shewhart & $\begin{array}{l}\text { Precise with minimum } \\
\text { variance }\end{array}$ \\
\hline Dr Juran & Readiness for use \\
\hline Philip Crosby & Conformance to requirements \\
\hline WE Deming & $\begin{array}{l}\text { Should be targeted at the } \\
\text { current and future needs of } \\
\text { the customer }\end{array}$ \\
\hline Armand V Feigenbaum & $\begin{array}{l}\text { Total quality management is } \\
\text { the best option for the } \\
\text { customer's benefit. }\end{array}$ \\
\hline ISO 9000:2005 & $\begin{array}{l}\text { The extent to which a set of } \\
\text { characteristics satisfies a set } \\
\text { of standards }\end{array}$ \\
\hline Dr. Kaoru Ishikawa & $\begin{array}{l}\text { Create, design, manufacture, } \\
\text { and service a high-quality } \\
\text { product that is both cost- } \\
\text { effective and useful to the } \\
\text { customer. }\end{array}$ \\
\hline Dr. Genichi Taguchi & $\begin{array}{l}\text { Damage generated by the } \\
\text { product to the society from } \\
\text { the moment the product is } \\
\text { shipped. }\end{array}$ \\
\hline
\end{tabular}

Table I- The bottom line of definitions of Quality by various quality gurus

These definitions show that quality is a constantly changing concept and reflects the progress of thought processes, as can be seen in the numerous endeavors to define 
quality over time. We can see that it has evolved into organization(s) more willingly or gladly accepting something total, encompassing not just product quality but also those elements/factors that can influence quality. All quality criteria which must be considered now include not only conformance to specifications, but also design and usability. In other words you can have a great product, but it's no good if it breaks down shortly after use. Furthermore not only product quality but also i) company quality that includes the surroundings or conditions in which operates and profession moral standards and ii) organisational quality inclusive of persuasive and systematic operation are new quality criterion that must be considered now.

Quality is a customer's ever-changing understanding of the value offered by a commodity. It is not a static perception that never changes, but rather a dynamic mechanism that evolves as a product matures due to creation usually with new or advanced features and other options become available for comparison due to competition. One of the best ways to assess a consumer approval of quality is looking into your product says "WOW! That met the requirements or There were no defects or That had all the value I wanted or The degree of excellence was acceptable".

Professor Noriaki Kano developed a Model while researching the factors that influence customer satisfaction and loyalty. His model clearly explains how requirements and features influence satisfaction, as shown in Figure 1.

As per Noori (1993) a quality approach to excellence is ensuring customer delight. The organization should make the customer feel special and deal with the customer as a matter of priority rather than as a secondary issue.

Watson defined "service and caring creating customer satisfaction" is quality and the level of service quality and customer satisfaction is connected to customer perceptions and customer expectations.

All of the above is based on customer-centric quality. Customer-centricity is a way of doing business with customers in such a way that they have a commendatory experience both before and after the transaction, resulting in increased customer loyality, customer satisfaction, and revenues. However, in the case of a low-quality manufacturer, faulty/defective goods will be returned for repair or replacement, rather than regular customers.

To increase the quality of goods, services, and life, quality principles and tools will be used in society. Process analysis, data collection and analysis processes, process auditing, and team collaboration quality are all basic quality control skills that can be used universally. Furthermore, advanced quality methods such as DOE (design of experiments), QFD (quality function deployment), and FMEA (failure modes and effects analysis are included. Professionals in a variety of fields can use it. Business development professionals inspiring the future must apply their expertise in strategic business opportunities to higher-level ventures and take a leap using the automated resources available in that direction for communication and collaboration, strategic thinking, information retrieval, and interpersonal skills and digital transformation-tools of the shrinking global marketplace now.

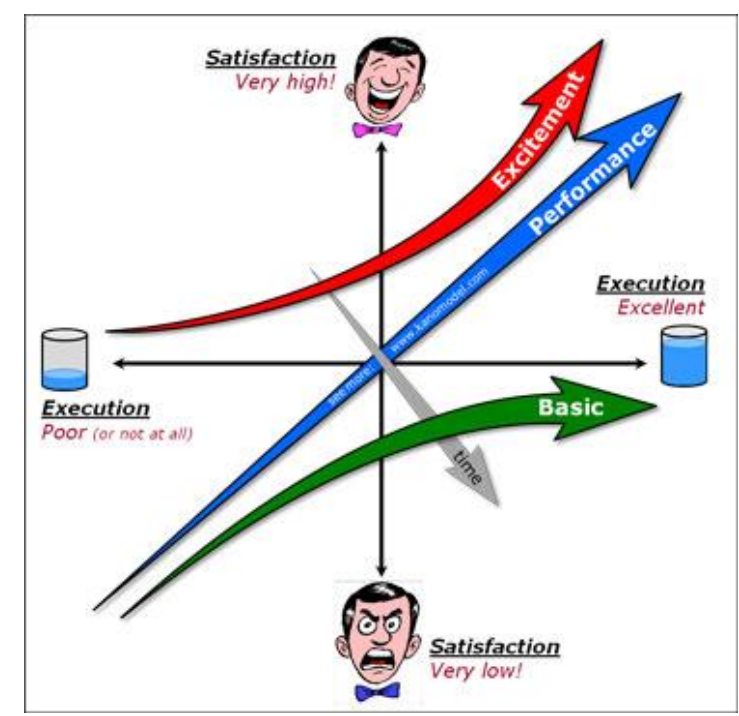

Fig.1 Kano Mode 1-Contributing factors to customer satisfaction and customer loyalty.

Many of the commonly used key terms pertaining to quality are:

1. Quality Control (QC),

2. Quality Assurance (QA),

3. Statistical Process Control (SPC)

4. Statistical Quality Control (SQC)

5. Total Quality Control (TQC) and

6. Total Quality Management (TQM)

Quality Control is a reactive mechanism that is based on detection. Quality Assurance is a proactive approach that focuses on prevention.

SPC stands for Statistical Process Control. It is used to "minimise variance and achieve the best possible target." Statistical Quality Control (SQC) refers to the process of measuring and documenting data against particular product specifications to ensure that they are met. Both play an important role in achieving organisational efficiency.

Total Quality Management (TQM) refers to continuous process improvement, while Total Quality Control (TQC) refers to maintaining quality standards in the process. Armand Feigenbaum was the first to propose the definition of TQC, which later became TQM. Dr. Kaoru Ishikawa says "Total Quality Control is a thinking revolution in management. To 


\section{International Journal of Engineering Applied Sciences and Technology, 2021 \\ Vol. 5, Issue 10, ISSN No. 2455-2143, Pages 247-256 \\ Published Online February 2021 in IJEAST (http://www.ijeast.com)}

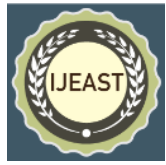

practice total quality control is to create, design, manufacture, and service a quality product that is most economical, most useful, and always satisfactory to the customer. To achieve this aim, everyone in the organization, including top management, all divisions, and all employees, must engage in and encourage quality control."

TQM is characterized as a system of interconnected quality practises that is linked to organizational success and customer satisfaction. The principles and strategies of total quality management (TQM) are now a well-accepted part of almost every manager's "tool kit."

TQM is a roadmap to organizational success and customer satisfaction, according to Choi and Eboch. Under the TQM scheme, there are four fields to evaluate: process quality management, human resource management, strategic quality planning, expertise in statistics and analysis.

Top management engagement, quality assessment and benchmarking, process management, product design, employee preparation and empowerment, supplier quality management, and customer participation and satisfaction are the seven concepts that make up an integrated TQM.

TQM is a demonstrated-and-true method for improving an organization's overall business operation, including product and service quality. Top management support, customer and supplier relationships, staff management, quality information, product/service design, and process management are all examples of TQM practices. For the success of companies towards their transition to a TQM organization, implementing these quality management methods is essential.

\section{EVOLUTION OF QUALITY IN MANUFACTURING}

The following section briefly traces the Birth of Quality Management Principles in manufacturing quality. This is illustrated in Fig-2.

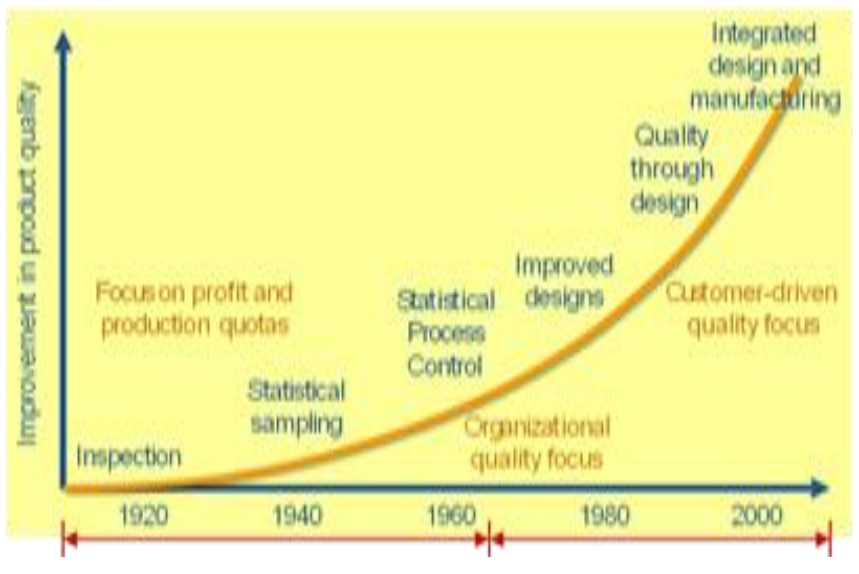

Fig.2 Manufacturing quality Management principles evolution
The origins of quality control can be traced back to the mediaeval guild system, with master craftsman status displaying higher-quality goods and services. Quickly moving forward to the industrial revolution the objective of quality has shifted to factory inspections and removal of faulty products.

Deming effectively applied Shewhart's statistical quality control techniques to war manufacturing throughout World War II and statistical process management helped the armed forces speed up inspections without compromising safety. Post-World War II, Shewhart's strategy plan-do-study-act was the basis for the modern plan-do-check-act cycle.

Manufacturers refined quality control practices in the following decades, moving beyond inspection to concentrate on techniques that included processes and personnel.

Japan's quality emphasis in the 1950s and 1960s enabled manufacturers to produce increasingly higher-quality products at lower prices. During this time, the Toyota Production System was developed, with a focus on reducing inventory and waste. One of the earliest modern forms of a Quality Management System (QMS) can be found in this creation.

Companies had to turn their attention to customer satisfaction during the postwar economic boom in order to make customers happy and win their hearts for business growth. By the 1970s, Japan had surpassed the United States in the production of cars and electronics.

Companies in the United States started to lose market share, prompting cost-cutting and import restriction policies. But unexpectedly, these approaches had little impact on product quality and nothing was done to increase the quality of the products. The United States' economy was affected by its failure to compete on quality. Total Quality Management (TQM) was created, paving the way for the growth of quality and operational excellence strategies in the United States.

TQM was a significant early force in quality control in the twenty-first century, but it has progressively faded from view in recent decades in lieu of newer methods like Six Sigma and lean manufacturing. What is the future of quality? We're seeing a few significant changes.

Integration: Companies can now break down departmental barriers thanks to technological advancements in Integrated Quality Management System. As Companies step in this direction they are combining the QMS with processes like safety and sustainability, which are often linked to consumer loyalty.

Big Data: Today's QMS collects more data than ever before, enabling businesses to gain a competitive edge by using advanced reporting and business intelligence resources.

Risk Management: Companies are recognising that quality and risk management are irrevocably related. Risk understanding is increasing among quality managers, as 


\section{International Journal of Engineering Applied Sciences and Technology, 2021 \\ Vol. 5, Issue 10, ISSN No. 2455-2143, Pages 247-256 \\ Published Online February 2021 in IJEAST (http://www.ijeast.com)}

shown by the use of risk-based methods in recent ISO 9001 revisions. In order to ensure consistency by improving quality, we've come a long way. The question now is how to build on that achievement. Statistical data analysis will always be at the forefront and obvious regardless of how an organisation handles it.

\section{QUALITY MANAGEMENT AND QUALITY ENGINEERING}

Quality management and quality engineering are mutually beneficial. The respective managers and engineers need different levels of skills. Though some quality engineering books briefly discuss quality management problems, a strong distinction between the two dimensions of quality is critical for further development and comprehension of the issues that impact each.

1. TQM is a common quality management theory. Total Quality Management (TQM) has its origins in the early 1920s, and it was further established in Japan in the 1940s led by Americans. TQM is a management theory and collection of strategies that emphasises among other things quality improvement, fulfilling customer needs, minimising rework, and long-term planning, system improvement, strategic benchmarking, team-based problem-solving, continuous monitoring of performance, and deeper relationships with suppliers (Ross, 1993). Committed leadership, TQM implementation and collaboration, closer customer and supplier partnerships, benchmarking, improved preparation, a transparent organisation, employee empowerment, a zerodefects approach, agile production, process improvement, and evaluation are all factors that contribute to TQM. Different studies also came up with different sets of TQM variables, which may be due to different researchers' definitional or methodological approaches.

TQM was labeled a failure, because it failed to produce the desired results due to a variety of factors including lack of toplevel engagement, customer neglect, and so on. Allocation of budget and resources, control by visibility, progress monitoring, and organizational change are some of the broad areas of management support for TQM implementations.

TQM is now widely accepted as a standardized management tool and top management's involvement in quality issues should not overshadow engineering's position and commitment to quality.

Training on the ISO 9000 quality management system and management-biased TQM should not be considered appropriate in and of themselves.

More attention should be paid to the engineering aspects of quality. According to our findings, quality engineering is used to reduce unit production costs as well as post-sale costs.
The aim of quality engineering is to create products that are resistant to a wide range of factors. Off-line quality control and on-line quality control are the two types of quality control operations. Off-line Methods investigates techniques for ensuring design optimization at all stages, while on-line Methods investigate techniques for process management.

Taguchi techniques and statistical process control methods are an interdisciplinary science that combines engineering design, manufacturing processes, and after-sale costs to enhance efficiency and minimise functional variations caused by environmental factors, degradation, and manufacturing imperfections.

Quality Gurus of the highest calibre Dr. Joseph M. Juran, Dr. W. Edwards Deming, Philip B. Crosby, Armand V. Feigenbaum, and Dr. Kaoru Ishikawa all made important contributions to the management aspects of quality as of today's version. Dr. Genichi Taguchi made a major contribution to quality engineering.

2. Six-Sigma is another useful quality control technique. Although the methodologies and procedures used in TQM and Six-Sigma tend to be somewhat similar, there is a fine line between them. Six-Sigma is a newer method than Total Quality Management, but it is not a substitute for it.

Six-Sigma is a quality-control methodology that focuses on reducing and ultimately removing defects in a system. It is a methodology that highlights on recognising and then eliminating different defects and barriers that may obstruct an organization's progress.

Six-Sigma needs specially qualified individuals whereas Total quality Management does not necessitate rigorous training.

Six-Sigma is a methodology that is more reliable and results-oriented because it is dependent on consumer reviews. Six-sigma, according to experts, would eventually attract more attention and praise than total quality control. The definition of Six-Sigma is to understand process fluctuation, the factors that influence it, and to reduce process variance using a range of statistical tools. Six-Sigma consists of five steps: i) Define ii) Measure iii) Analyse iv) Improve and v) Control.

3. Lean manufacturing: Toyota production system is another name for lean thinking. The Toyota production system introduced the Lean concept to enhance the quality, improves the efficiency and effectiveness of process performance. Lean has been defined as a theory, an approach, a methodology and a transformational management strategy to improve production processes. The emphasis in Lean is on flow. The aim of the Lean approach is to boost competitive advantages while minimising waste. Waste is characterised as anything that is not required in the production of a product or service. 


\section{International Journal of Engineering Applied Sciences and Technology, 2021 Vol. 5, Issue 10, ISSN No. 2455-2143, Pages 247-256 \\ Published Online February 2021 in IJEAST (http://www.ijeast.com)}

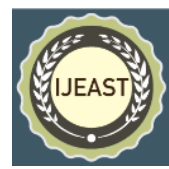

The five essential steps in Lean are as given blow
1. Pinpoint value,
2. Pinpoint the value stream,
3. Improve flow,
4. Permit customer pull,
5. Perfect the process.

Everyone in a company would be concerned with quality. Quality professionals should specialise in quality skills to provide quality information and manage the quality system in the future. They should be knowledgeable about key quality technologies such as metrology, quality database administration and quality tools like quality function deployment, statistical process control, and design of experiments besides essential competencies: creative thinking and ability to innovate in order to provide advice on quality techniques.

\section{ISSUES IN QUALITY ENGINEERING}

The Quality Engineering and management are very important in the development and delivery phases. Out of all the development and delivery phases Testing is one of the phases that are often cut out focusing on testing phase is essential. Underestimating testing phase is dangerous as it may lead to serious consequences in the future. We are building the product so well that we can test it in a short period of time should never be the phrase mentioned. Some aspects of testing that are sometimes neglected are:

a) Little time allocated for testing: Full scale testing, even it takes a longer time is important to locate errors, then correct the errors, test again, pass all the tests and sign it off. Testing is not even something that you do once and be done with it: it's a cyclical effort until the tests pass. Testers should be available for the whole time so that they can quickly respond when developments come back to be tested again.

b) Scope of testing too narrow: Testing the end use is not enough. Expecting end users to understand how the product works from the beginning is not right as they might be doing it wrong because they don't know any better. Different testing approaches should be tried and encourage trying "creative" ways in order to realize whether your product is trouble-free. Testing should cover all aspects and events, not just the expected ones.

c) Formal procedure not established: Complete adequate testing by each department or organizational sector should be carried out to say that they are happy.

d) Inexperienced testers: Companies having a permanent testing unit to test all kinds of developments and products are better. In absence of testing knowledge in house, companies should hire qualified and trained testers with a particular background or skill especially when new systems are being implemented. Better results are obtained from testing if testers have the knowledge they need to test and feel supported.

e) Lousy documentation: The testing cannot be serious unless there is something in writing that tells what is done and what the outcome was. As a minimum, following should be recorded. This is the type of data that the developers will need in order to make the appropriate changes and solve the problem.

1) Who performed the test?

2) Date of tests.

3) Environment testing carried out.

4) Development, Quality assurance, etc.

5) Main data points used in the testing

6) Test result.

7) If a test has failed, record reasons for its failure.

\section{QUALITY MANAGEMENT ISSUES FACING THE MANUFACTURING INDUSTRY}

Organizations serious about improving business processes today understand various effects of quality on their operations. Quality management role on external quality functions like audit management, inspections, and compliance appears to be difficult. Quality management issues facing the manufacturing industry are:

1) Organization quality culture i.e., quality follow-up or compliance.

2) KPI's, benchmarking and advantages over a period of time.

3) Bold quality governance and command.

4) Exponential data growth management technology.

5) Closed loop quality management strategies.

6) Value chain analysis and identifying factors affecting quality.

7) Closed-Loop Quality: Connecting Engineering, Manufacturing and Quality

8) Technology strategy, principles, objectives, and tactics to achieve organizational objectives.

Traditional approaches for dealing with nonconformances have lost favour in the manufacturing industries, which is plagued by nonconformance issues. Distributed organisations lack standardization. They waste a lot of time trying to eliminate redundancies and inefficiencies. In industries such as automotive, aerospace \& defense, oil \& gas and medical devices, manufacturers have been monitoring and handling nonconformance procedures for decades to reduce the cost of poor quality. These businesses must adopt an automated, integrated, centralised, and structured strategy. Nonconformance control optimization requires effective issue monitoring. This problem can be solved by using defect management tools and issue tracking software to streamline nonconformance processes through the entire organisation. 


\section{International Journal of Engineering Applied Sciences and Technology, 2021 Vol. 5, Issue 10, ISSN No. 2455-2143, Pages 247-256 \\ Published Online February 2021 in IJEAST (http://www.ijeast.com)}

\section{APPROACH FOR BUSINESS SUSTENANCE}

1. Organization quality culture i.e., quality follow-up or compliance: To foster a strong quality culture, top-level support or leadership in developing a "Quality Vision" that works is essential.

The "lack of employee ownership of quality problems" is a common trend in the LNS Research 2012-2013 Quality Management Survey. This has been the most critical of the top quality control challenges confronting the manufacturing industry. "Their company considers quality as a department, not a liability across the enterprise," said more than half of executives interviewed by LNS Research.

Personnel outside of quality management are completely dependent on Executive Leadership to cultivate a total, holistic quality culture. Quality programs would likely yield marginal results without such encouragement.

2. Quality to every section: Strong quality management does not happen in an empty area or space; Entire organizations' departments have a legitimate responsibility in continuously developing quality management systems. Companies must redefine the position of quality departments within the corporate chain of command in today's global manufacturing industry. Employee support on the shop floor and the ability to continue working at the best of their abilities is just as essential as senior management requires acceptance of a decision on quality related issues.

3. Enterprise quality management: Is quality enforcement appearing like an endless state of bewilderment or confusion? Is perpetual risk reduction an illusion? For transforming the company's quality management processes implementing a proven powerful and robust enterprise quality management and compliance platform is essential. A robust Quality Management System(s) aids to cut the amount of time and resources required to meet regulatory requirements and also in the pursuit of quality culture and the reduction of risk. A QMS platform that provides best-in-class data visibility and open integration capabilities is expected, to transform the business of an enterprise.. The quality team should have a thorough understanding of quality problems and QMS such that they can provide timely deployments and inform customer service. To break free from the state or quality of being confused or puzzled, experience the peace of mind comes with implementing a proven, high-quality risk mitigation solution and technology for quality control. Such QMS creates a road map for quality success by addressing quality challenges. The platform should:

1) Identify areas of potential growth

2) Control cost of quality

3) Combine tools and big data for quality processes

4) Close the loop across the value chain
5) Foster conformance for ISO 9001, IATF 16949, ISO 13485, ISO 13485, AS9100 and more.

In addition, a free digital library of tools that include analysis, white papers, webinars, and much more, to provide insights into quality management issues be hosted. These tools should be created to assist companies in better addressing quality compliance problems, risk, data visibility, and other aspects of quality management, as well as the current quality issues and how businesses are responding to them.

4. Quality and compliance: Organizations should develop proactive quality enforcement hub rather than reactive management throughout a business enterprise.

\section{QUALITY MANAGEMENT FOR MANUFACTURING}

Quality control is an essential part of the manufacturing process from inception to transportation of the finished product. Quality management for manufacturing can seem like a taxing task equal with the challenge of balancing manufacturing processes that demand

1) Exacting precision

2) Managing coordination between engineering and operations

3) Maximizing global supply networks and

4) Carrying out efficient regulatory processes

Manufacturers often find difficulty in making quality and compliance part of the manufacturing process because of their quality management tools, which are based on homegrown or legacy systems, are not up to the challenge and compel them to take a reactive approach. This outdated approach is not only a hindrance to long-term growth goals, but it can also be costly and dangerous. Quality management and compliance should be made it part of the manufacturing process means for an Effective march toward operational excellence.

A QMS tool that provides solutions for all, regardless of the complexity of processes, specific faultfinding issues with compliance is necessary. It should push quality control systems to new heights. It should improve the interactions between individuals, processes, and technology, both inside and outside of your business irrespective of general manufacturing or a niche industry like aerospace and defence, automotive, medical equipment, or food and beverage. A single integrated solution including ISO 9001, ISO 14000, AS9100, IATF 16949, ISO 13485, FDA GxP, FDA 21 CFR Part 11 and HACCP/ISO 22000 is required to bring in total quality management and elevate the quality. To lead the way out, allow a culture of continuous improvement by implementing best-in-class quality management systems, taking a break from the fast-paced environment of entangled quality enforcement issues. The capacity of quality management systems should not only streamline, harmonise, 


\section{International Journal of Engineering Applied Sciences and Technology, 2021 Vol. 5, Issue 10, ISSN No. 2455-2143, Pages 247-256 \\ Published Online February 2021 in IJEAST (http://www.ijeast.com)}

and centralise quality and compliance data, but should also result in quicker, more efficient processes and workflows in the workplace in the fast-paced global economy.

\section{RevolutionizING ISO 9001:2015 COMPLIANCE}

Today, iso 9001 is the central stone of manufacturing quality control. Compliance with the ISO 9000 family of standards is considered a basic necessity in most manufacturing environments. Streamlining, processes and document control in manufacturing quality management, allowing you to evaluate enterprise-wide quality and data compliance in real time in order to stay current and ahead with global competition, regardless of the industry.

\section{RISK MITIGATION:}

Quality Assurance automation gives you exclusive, realtime insights into potential risks, analyses their effect on the business, and develops strategies to minimise or mitigate the risk. Non compliance with regulatory requirements and quality standards is greatly reduced by automated quality drivers. Qa automation tools reduce risk while also improving processes, reliability, and overall quality. It is riskier to not use technology. According to thomson reuters, a lot of companies are backing on technology to minimise risk.

\section{DATA VISIBILITY:}

DATA visibility: Data is the key differentiator when it comes to quality management issues. Data visibility is essential across any organization but without a way to segregate and analyze those data generation of such massive data is worthless. Software for Quality Management Systems (QMS) provides high visibility of every phase of the product lifecycle. Andrew McAfee and Erik Brynjolfsson in Harvard Business Review brought out that Companies that utilize their data to make decisions are 5 percent more productive and 6 percent more profitable than those that do not.

\section{CONCLUSION}

A dedicated nonconformance issue tracking software is the need of every organization, today for corrective actions as a proactive approach to nonconformance management, overall cost of quality reduction, quantifies performance based on real-time metrics and track improvements over time, foster improved supplier and customer communication and relationships from an enterprise-wide perspective.

Issue monitoring software program gets rid of situations of coordinating different kinds of unrelated quality management and control information from around the organization. It presents real-time information amidst the different stages of nonconformance correction, at the same time allowing quality management groups to redesign workflows to address nonconformance problems more quickly.

Issue monitoring software is an interactive, real-time application that combines the strengths of diverse nonconformance. Nonconformance optimization that is aided by issue monitoring tools eliminates the need for manual and paper-based nonconformance control. It equips professionals from the shop floor to the dignitary on business with the data they need to handle and prevent nonconformance problems. Nonconformance data can be used by the plant level and top management to detect performance patterns. This serves as a catalyst for quality improvement activities in the company.

Nonconformance has been a problem in manufacturing since the beginning, and it continues to be a problem even as equipment becomes more precise. Nonconformance costs, from material disposal to squandered manpower, inflate costs and minimise profitability. If nonconforming parts and goods are not detected before they are accessible to consumers, it may jeopardise customer protection or brand credibility. Manufacturers who depend on spreadsheets to monitor nonconformance, unlike in the past, end up with soiled and inaccessible data. It is preferable to use compliance monitoring tools to prevent this. It aids in the monitoring of nonconformance back to its source. The harm that a single incident has caused can be quickly remedied. However, if it turns out to be a more widespread problem, it's vital to have the resources to track it down to the root and take the appropriate corrective action. Advanced compliance management platforms and digitized intelligent libraries ensures the data is in the right hands and that the loop is closed so that things are done correctly the first time. Meeting new sustainability standards, which are constantly changing, is a challenge for manufacturing, particularly when it comes to monitoring, documenting, and evaluating environmental safety criteria to connect by means of a single interface in order to minimise the risk of issues being overlooked. An integrated solution for i) keeping up with quality demands, ii) consistently meeting requirements across supply chains and various manufacturing sites, iii) maintaining consistent performance on an enterprise-wide basis by all sets of standards and iv) monitoring as well as management of current issues to a single control point lies with various international standards like

1) AS9100 for Aerospace and Defence organizations,

2) IATF 16949 for keeping pace with quality demands in automotive industries,

3) ISO 13485 for taking control of compliance in medical devices

4) HACCP/ISO 22000 standards compliance for food safety and

5) EH\&S/ISO 14000 standards for environmental safety and health are Some for information: 


\section{International Journal of Engineering Applied Sciences and Technology, 2021 \\ Vol. 5, Issue 10, ISSN No. 2455-2143, Pages 247-256 \\ Published Online February 2021 in IJEAST (http://www.ijeast.com)}

\section{REFERENCES}

1. Aquilani,B., Silvestri, C., Ruggieri, A., \& Gatti, C. (2017) - A systematic literature review on total quality management critical success factors and the identification of new avenues of research.The TQM Journal, 29(1), pp184-213.

2. Bajaj,S., Garg, R., \& Sethi, M. (2018) - Total quality management: A critical literature review using Pareto analysis. International Journal of Productivity and Performance Management, 67(1), pp128-154.

3. Barouch, G., \& Kleinhans, S. (2015) - Learning from criticisms of quality management. International Journal of Quality and Service Sciences, 7(2/3), pp201-216.

4. Barouch, G., \& Ponsignon, F. (2016).-The epistemological basis for quality management. Total Quality Management \& Business Excellence, 27(7-8), pp944-962.

5. Brown, A. (2013). Quality: Where have we come from and what can we expect? The TQM Journal, 25(6), pp585-596.

6. Camerud, D. (2017).-Exploring research on quality and reliability management through text mining methodology. International Journal of Quality \& Reliability Management, 34(7), pp975-1014.

7. 18D. Carnerud and I. Backstrom Camerud, D. (2018).-25 years of quality management research-outlines and trends. International Journal of Quality \& Reliability Management, 35(1), pp208-231.

8. Cole, R. E., \& Scott, W. R. (2000).-The quality movement and organization theory. Thousand Oaks, CA: Sage Publications.

9. Dahlgaard-Park, 8. M., Chen, C. K., Jang, J. Y., \& Dahlgaard, J. J. (2013).-Diagnosing and prognosticating the quality movement - a review on the 25 years quality literature (1987-2011). Total Quality Management \& Business Excellence, 24(1-2), pp1-18.

10. Dahlgaard-Park, S, Rees, L, Chen, \& C. (2018).-The evolution and convergence of total quality management and management theories. Total Quality Management, 29(9-10), pp1108-1128.

11. Delen, D., \& Crossland, M. D. (2008).-Seeding the survey and analysis of research literature with text mining. Expert Systems with Applications, 34(3), pp1707-1720.

12. Dereli, T., Durmusoglu, A., Delibas, D., \& Avlanmaz, N. (2011).-An analysis of the papers published in total quality management \& business excellence from 1995 through 2008. Total Quality Management \& Business Excellence, 22(3), 373-386.

13. Feigenbaum, A. V. (1999).-The new quality for the twenty-first century. The TQM Magazine, 11(6), pp376-383.

14. Feigenbaum, A. V., \& Feigenbaum, D. S. (1999) New quality for the 21st century. Quality Progress, 32(12), pp 27-31.

15. Feldman, R., \& Sanger, J. (2007) - The text mining handbook: Advanced approaches in analyzing unstructured data. Cambridge, USA: Cambridge University Press.

16. Fredriksson, M., \& Isaksson, R. (2018) - Making sense of quality philosophies. Total Quality Management \& Business Excellence, 29(11-12), pp1452-1465.

17. Juran, J. M. (1995) - Summary, trends, and prognosis. In J. M. Juran (Ed.), A history of managing for quality: The evolution, trends, and future directions of managing for quality (pp. 603-653).Milwaukee, WI: ASQ Press.

18. Kumar, P., Maiti, J., \& Gunasekaran, A. (2018) Impact of quality management systems on firm performance. International Journal of Quality \& Reliability Management, 35(5), pp1034-1059.

19. Lo, Q. Q., \& Chai, K. H. (2012) - Quantitative analysis of quality management literature published in total quality management and business excellence (1996-2010). Total Quality Management \& Business Excellence, 23(5-6), pp629-651.

20. Maguad, B. A. (2006) - The modern quality movement: Origins, development and trends. Total Quality Management \& Business Excellence, 17(2), pp179-203.

21. Marban, O., Mariscal, G., \& Segovia, J. (2009, February) - A data mining \& knowledge discovery process model. In J. Ponce, \& A. Karahoca (Eds.), Data mining and knowledge discovery in real life applications (pp. 1-18). Vienna: Intech Open.

22. Mariscal, G., Marban, O., \& Fernandez, C. (2010) A survey of data mining and knowledge discovery process models and methodologies. The Knowledge Engineering Review, 25(02), pp137-166.

23. Martinez-Lorente, A. R., Dewhurst, F., \& Dale, B. G. (1998) -Total quality management: Origins and evolution of the term. The TQM Magazine, 10(5), pp378-386.

24. Reeves, C. A., \& Bednar, D. A. (1994). - Defining quality: Alternatives and implications. Academy of Management Review, 19(3), pp419-445. 
25. Handbook of data mining and knowledge discovery (pp. 185-192). Oxford: Oxford University Press.

26. Van Kemenade, E., \& Hardjono, T. W. (2019) -. Twenty-first century total quality management: The emergence paradigm. The TQM Journal, 3 1(2), pp150-166.

27. Weckenmann, A., Akkasoglu, G., \& Werner, T. (2015) - Quality management-history and trends. The TQM Journal, 27(3), pp281-293.

28. In Proceedings of the 4th international conference on the practical applications of knowledge discovery and data mining (pp. 29-39). Manchester: Practical Application Company.

29. Zairi, M. (2013). The TQM legacy gurus' contributions and theoretical impact. The TQM Journal, 25(6), pp659-676. 